\title{
The pharmacotherapy of low back pain
}

\section{Oppel BW Greeff}

Department of Pharmacology, University of Pretoria, South Africa

\section{Introduction}

About $60-80 \%$ of patients visiting a physician have at some stage in their lives suffered from low back pain. The annual incidence in adults aged 35-55 years in developed countries is up to $45 \%$. $^{1}$ The differential diagnosis is broad and includes muscular strain, primary spine disease like disc herniation or degenerative arthritis, systemic diseases like metastatic cancer and regional diseases like aortic aneurisms. In the majority of cases, a specific diagnosis cannot be made.

Most patients will improve in 1-4 weeks and will only need treatment for the acute symptoms after the initial history and physical examination. If, however, the pain recurs or worsens, the patient must be thoroughly examined and a specific diagnosis can become a challenge.

\section{Causes of lower back pain}

There are multiple causes of lower back pain and the physician will always attempt to get to the correct cause in order to ensure that the most effective treatment is recommended. Modern imaging techniques have contributed significantly to getting to the correct diagnosis. The following conditions may cause lower back pain: cancer, cauda equina syndrome, herniated intervertebral disc, severe or progressive neurological deficits, spinal stenosis, vertebral compression fracture or vertebral infection.

When communicating with the patient, the physician must practice immediate medical care if the patient complains of severe back pain that:

1. Followed a fall, blow to the back or other injury

2. Is constant or severe

3. Worsens during rest or at night

4. Spreads down one or both legs

5. Causes weakness, numbness or tingling in one or both legs

6. Is associated with new bowel or bladder problems

7. Is accompanied by fever

\section{Is associated with pain or throbbing in the abdomen}

9. Is accompanied by unexplained weight loss.

This will ensure that serious causes of lower back pain are not overseen.

\section{Management of lower back pain}

The State of Oregon in the USA recently published guidelines for the evaluation and management of low back pain. Table I gives a good summary of the current medical practice. ${ }^{2}$

From this table it is apparent that self-care, nonpharmacologic therapy and interdisciplinary therapy are important in the total intervention programme. We will focus on the pharmacologic therapy of lower back pain.

\section{Pharmacotherapy of lower back pain}

The most commonly used medicines in the treatment of lower back pain are the analgesics. Therapy will be discussed as follows:

1. Non-opioid analgesics

2. Opioids

3. Skeletal muscle relaxants

4. Other central nervous system (CNS) drugs

\section{The non-opioid analgesics}

- Paracetamol (acetaminophen) is the most commonly used and prescribed analgesic for lower back pain. It has equivalent analgesic efficacy to aspirin with no useful anti-inflammatory action. Paracetamol has a central anti-nociceptive effect through selective inhibition of prostaglandin $\mathrm{H}_{2}$ synthetase. It serves as a reducing co-substrate for the peroxidase-active site of the enzyme (=a-POX inhibitor). ${ }^{3}$ It is conjugated in the liver as the inactive glucoronate and sulphate. ${ }^{4}$ Adverse effects are rare in therapeutic usage - occasional rash and allergy. Dosage orally should not exceed $4 \mathrm{~g} /$ day and intravenously a loading dose of $2 \mathrm{~g}$ is administered, followed by $1 \mathrm{~g}$ 4-hourly to a maximum of $4 \mathrm{~g} /$ day. 
Table I: Interventions

\begin{tabular}{|c|c|c|c|}
\hline Intervention category & Intervention & Acute $<4$ weeks & Subacute and chronic $>4$ weeks \\
\hline \multirow[t]{3}{*}{ Self-care } & Advice to remain active & $\bullet$ & $\bullet$ \\
\hline & Books, handouts & $\bullet$ & $\bullet$ \\
\hline & Application of superficial heat & $\bullet$ & \\
\hline \multirow[t]{7}{*}{ Nonpharmacologic therapy } & Spinal manipulation & $\bullet$ & $\bullet$ \\
\hline & Exercise therapy & & $\bullet$ \\
\hline & Massage & & $\bullet$ \\
\hline & Acupuncture & & $\bullet$ \\
\hline & Yoga & & $\bullet$ \\
\hline & Cognitive-behavioural therapy & & $\bullet$ \\
\hline & Progressive relaxation & & $\bullet$ \\
\hline \multirow{6}{*}{$\begin{array}{l}\text { Pharamacologic therapy } \\
\text { (Carefully consider risks/harms) }\end{array}$} & Acetaminophen & $\bullet$ & $\bullet$ \\
\hline & NSAIDs & $\bullet \boldsymbol{\Delta}$ & $\bullet \boldsymbol{\Delta}$ \\
\hline & $\begin{array}{l}\text { Skeletal muscle relaxants e.g. } \\
\text { orphenadrine, methocarbamol and } \\
\text { cyclobenzaprine }\end{array}$ & $\bullet$ & \\
\hline & Antidepressants (TCA) & & $\bullet$ \\
\hline & Benzodiazepines & $\bullet \boldsymbol{\Delta}$ & $\bullet \boldsymbol{\Delta}$ \\
\hline & Tramadol, opioids & $\bullet \boldsymbol{\Delta}$ & $\bullet \boldsymbol{\Delta}$ \\
\hline Interdisciplinary therapy & Intensive interdisciplinary rehabilitation & & $\bullet$ \\
\hline
\end{tabular}

- Aspirin is the oldest and most well-known and widely used analgesic. It has analgesic, antipyretic and anti-inflammatory actions and causes respiratory stimulation. It can cause respiratory alkalosis, renal loss of electrolytes with dehydration plus a disturbance of glucose metabolism. Aspirin has a uricosuric effect in dosages between 5-8g/day. It reduces platelet adhesion and causes hypothrombonaemia in dosages $>5 \mathrm{~g} /$ day. ${ }^{5}$ The normal dosage of aspirin is $325-650 \mathrm{mg}$ every 4-6 hours for pain and fever.

- The non-steroidal anti-inflammatory drugs (NSAIDs)

The NSAIDs inhibit cyclo-oxygenase (prostaglandin synthase) that is responsible for conversion of arachidonic acid to cyclic endoperoxidases. There are two iso-forms - COX-1 and 2, which led to the sub-group of COX-2 selective inhibitors. Their main actions are analgesic, anti-inflammatory, antipyretic and antiplatelet (prevent thromboxane production). Topical NSAIDs (eg diclofenac) can be used in combination with oral therapy. Diclofenac has both COX-1 and COX-2 inhibitor activity and in combination with misoprostol $200 \mathrm{mcg}$ protects the gastric mucosa in patients on long term therapy. The side-effects include gastric and intestinal mucosal damage, disturbances of fluid and electrolyte balance and they can cause analgesic nephropathy. ${ }^{6}$ Dosages vary in the different sub-classes.

\section{The opioids}

There are four types of G-protein-coupled opioid receptors, each having a different pharmacological effect - mu, kappa, delta and the ORL-1 receptors. The affinity for these receptors parallels their analgesic potency. Morphine is the prototype opioid and has the following effects: analgesia, euphoria, respiratory depression, depression of the cough reflex, nausea and vomiting and pupillary constriction. It also has significant effects on the gastointestinal tract (GIT) - increased tone, decreased motility, constriction of the biliary sphincter and delayed absorption of other drugs. Morphine is used for severe or overwhelming pain.7 Oral dosage is $30 \mathrm{mg}$ every 3-4 hours and $10 \mathrm{mg} \mathrm{q3}-4 \mathrm{~h}$ parenterally.

\section{The skeletal muscle relaxants}

The term is commonly used to refer to a heterogeneous group of pharmacologically unrelated medications approved to treat two distinct conditions: spasticity from upper motor neuron syndromes and pain or spasms from musculoskeletal conditions such as non-specific low back pain. These include carisoprodol, chlorzoxazone, cyclobenzaprine, metaxalone, methocarbamol and orphenadrine. ${ }^{8}$

- Orphenadrine is a nonselective mACh receptor antagonist and an $\mathrm{H} 1$ receptor antagonist which is used to treat muscle pain and with motor control in Parkinson's disease. It also has a NMDA 
receptor antagonist activity which may contribute to its muscle relaxing activity. The dosage is $100 \mathrm{mg}$ two-three times daily.

- Cyclobenzaprine is the best studied drug for relief of skeletal muscle spasms and has also shown effectiveness in the treatment of fibromyalgia. It is a centrally acting skeletal muscle relaxant with antidepressant activity. ${ }^{9}$ Cyclobenzaprine seems to act primarily at the brain stem to reduce tonic muscle motor activity, influencing both gamma and alpha motor neurons leading to a reduction in muscle spasms. ${ }^{10}$ Dosage is $15-30 \mathrm{mg}$ once daily.

- Methocarbamol is a central acting muscle relaxant which may inhibit carbonic anhydrase and the NMDA receptor. Peripherally it prolongs the muscle refractory period. The initial dosage is $1,5 \mathrm{~g}$ four times a day. ${ }^{11,12}$

A Cochrane review for acute low back pain which included eight trials found that these drugs were superior to placebo for short term pain relief and global efficacy. It also found these drugs are associated with more total adverse events and sedation than placebo, though most events were self-limited and serious complications appeared rare. ${ }^{8}$

\section{Other CNS drugs used in lower back pain}

- Antidepressants. The tricyclic antidepressants like amitriptyline are often used in the treatment of chronic back pain. They block the uptake of amines by nerve terminals. Duloxetine has been studied extensively in the use in pain conditions and is approved for the treatment of fibromyalgia and chronic musculoskeletal pain, including discomfort from osteoarthritis and chronic lower back pain. ${ }^{17}$

- The benzodiazepines, specifically diazepam, are used for muscle spasms, but are not approved for this indication. ${ }^{18}$

- Gabapentin is an anti-epileptic drug which modulates the action of two enzymes involved in GABA biosynthesis and binds to the alpha2delta subunit of voltage gated calcium ion channels. ${ }^{19}$ It is recommended as a first line medication for the treatment of neuropathic pain in diabetes, herpes and central neuropathic pain. ${ }^{20}$

- Pregabalin is also an anti-epileptic that acts on the calcium ion channels, which is used in neuropathic pain. ${ }^{21}$

The physician writes many prescriptions to patients suffering from lower back pain. If the patient's pain is not well controlled, make sure the prescription has an analgesic, a NSAID and a CNS drug used for neuropathic pain. It often helps to replace one of these drugs with a drug in the same category. There are various options - strive to help the patient to get the best pain control.

\section{References}

1. Van Schoor J. A review of weak opioids used in combination with other analgesics to treat low back pain. S Afr Pharm J 2012;79(2):10-12.
2. Livingston C, King V, Little A, Pettinari C, Thielke A, Gordon C. [Internet]. State of Oregon Evidence-based Clinical Guidelines Project. Evaluation and management of low back pain: A clinical practice guideline based on the joint practice guideline of the American College of Physicians and the American Pain Society (Diagnosis and treatment of low back pain). Salem: Office for Oregon Health Policy and Research. 2011; [cited 2016 Jun 13] Available from: http://www. oregon.gov/OHA/OHPR/HERC/Evidence-Based-Guidelines.shtml

3. Hinz B, Cheremina O, Brune K. Acetaminophen (paracetamol) is a selective cyclooxygenase-2 inhibitor in man. FASEB J. 2008 Feb;22(2):383-390.

4. Product information Codapane Forte. [Internet]. [cited 2016 Jun 13]. Available from: https://www.ebs.tga.gov.au/ebs/picmi/picmirepository.nsf/ pdf?OpenAgent\&id=CP-2010-PI-05623-3\&d=2016061316114622483.

5. Goodman LS, Gilman A, Brunton LL, Lazo JS, Parker KL. Goodman \& Gilman's the pharmacological basis of therapeutics. 11th ed. / ed. New York : McGraw-Hill, 2006.

6. Knights KM, Mangoni AA, Miners JO. Defining the COX inhibitor selectivity of NSAIDs: implications for understanding toxicity. Expert Rev Clin Pharmacol 2010;3(6):769-776.

7. Rang HP, Dale MM. Rang and Dale's pharmacology. 7th ed. ed. Edinburgh ;: Elsevier/Churchill Livingstone; 2012.

8. Chou R, Hoyt Huffman L. [Internet]. APS Clinical Guideline for the Evaluation and Management of Low Back Pain Evidence Review. [cited 2016 Jun 13]. Available from: http://americanpainsociety.org/uploads/education/guidelines/evaluationmanagement-lowback-pain.pdf.

9. FLEXERIL (CYCLOBENZAPRINE HCl) Tablets. [Internet]. [cited 2016 Jun 13]. Available from: http://www.accessdata.fda.gov/drugsatfda_docs/ label/2003/17821se8-045_flexeril_lbl.pdf.

10. Chou R, Peterson K, Helfand M. Comparative efficacy and safety of skeletal muscle relaxants for spasticity and musculoskeletal conditions: a systematic review. J.Pain Symptom Manage. 2004;28(2):140-175.

11. Parr JS, Khalifah RG. Inhibition of carbonic anhydrases I and II by N-unsubstituted carbamate esters. J.Biol.Chem. 1992 Dec 15;267(35):25044-25050.

12. TRUITT EB,Jr, LITTLE JM. A pharmacologic comparison of methocarbamol (AHR-85), the monocarbamate of 3-(0-methoxyphenoxy)-1,2-propanediol with chemically related interneuronal depressant drugs. J.Pharmacol.Exp.Ther. 1958 Feb;122(2):239-246.

13. Rumore $M$, Schlichting D. Analgesic effects of antihistaminics. Life Sci. 1985;36(5):403-416.

14. Syvälahti E, Kunelios R, Lauren L. Effects of antiparkinsonian drugs on muscarinic receptor binding in rat brain, heart and lung. Pharmacol.Toxicol. 1988;62(2):90-94.

15. Kornhuber J, Parsons C, Hartmann S, Retz W, Kamolz S, Thome J, et al. Orphenadrine is an uncompetitive N-methyl-D-aspartate (NMDA) receptor antagonist: binding and patch clamp studies. J Neural Transm Gen Sect 1995;102(3):237-246.

16. Moore RA, Derry S, Aldington D, Cole P, Wiffen PJ. Amitriptyline for neuropathic pain in adults. Cochrane Database Syst Rev 2015(7).

17. Stahl SM, Grady MM, Moret C, Briley M. SNRIs: the pharmacology, clinical efficacy, and tolerability in comparison with other classes of antidepressants. CNS spectrums 2005;10(09):732-747.

18. Calcaterra NE, Barrow JC. Classics in chemical neuroscience: diazepam (valium) ACS Chem Neurosci 2014;5(4):253-260.

19. Taylor CP. Mechanisms of action of gabapentin. Rev.Neurol.(Paris) 1997;153 Suppl 1:S39-45.

20. Attal N, Cruccu G, Baron Ra, Haanpää M, Hansson P, Jensen TS, et al. EFNS guidelines on the pharmacological treatment of neuropathic pain: 2010 revision. Eur J Neurol 2010;17(9):1113-e88.

21. National Center for Biotechnology Information. PubChem Compound Database; $\mathrm{CID}=5486971$. [Internet]. [cited 2016 Jun 13]. Available from: https://pubchem. ncbi.nlm.nih.gov/compound/5486971 